\title{
A Red-Emission Fluorescence Probe Based on 1,4-Addition Reaction Mechanism for the Detection of Biothiols in Vitro and in Vivo
}

Yaoyun HU,** Zhuye SHANG,** Pengli GU,** Guangjie HE, ${ }^{*}{ }^{\dagger}$ Run ZHANG, $* * *$ Qingtao $\mathrm{MENG},{ }^{* \dagger}$ and Zhiqiang $\mathrm{ZHANG} * \dagger$

* School of Chemical Engineering, University of Science and Technology Liaoning, Anshan, Liaoning, 114051, P. R. China.

** Medicine, Xinxiang Medical University, 601 Jinsui Road, Xinxiang, 453003, Henan Province, P. R. China.

*** Australian Institute for Bioengineering and Nanotechnology, The University of Queensland, Brisbane, 4072, Australia.

$\dagger$ To whom correspondence should be addressed.

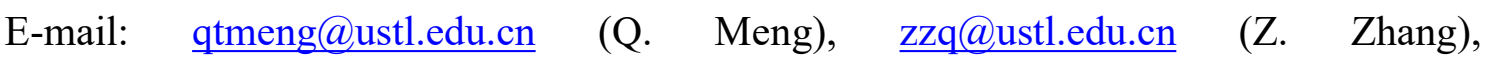
guangjiehe@163.com (G. He)

$\$$ Yaoyun HU and Zhuye SHANG contributed equally to this work and they should be regarded as co-first authors 


\begin{abstract}
In this work, a new fluorescence probe (DC) with a donor- $\pi$-acceptor (D- $\pi-A)$ structure was designed and synthesized for the detection of three kinds of biothiols (Cys, Hcy and GSH) in live cells and organisms. DC displayed an intense red-emission centered at $625 \mathrm{~nm}$. In the presence of biothiols, nucleophilic addition reaction between $\mathrm{C}=\mathrm{C}$ double bond of $\mathrm{DC}$ and sulfhydryl group (-SH) of biothiols occurred, resulting in obvious fluorescence quenching responses. DC exhibited highly selectivity towards biothiols over other common bioactive species with low detection limits $(0.26,0.43$, and $0.44 \mu \mathrm{M}$ for Cys, Hcy and GSH, respectively). In addition, DC displayed a rapid response to biothiols within $4 \mathrm{~min}$. The applications of $\mathbf{D C}$ in biothiols detection and imaging were then successfully demonstrated for the real-time monitoring endogenous and exogenous biothiols in live cells and live animals.
\end{abstract}




\section{Introduction}

Biothiols, including cysteine (Cys), homocysteine (Hcy) and glutathione (GSH), play important roles in maintaining redox homeostasis in biological systems through equilibrium between the reduced free sulfhydryl group (-SH) and oxidized disulfide forms. ${ }^{1-3}$ This biothiol species is reported to be involved in many cellular functions, such as maintaining signal transduction and regulating gene expression, etc. ${ }^{4,5}$ The abnormal levels of biothiols in bodies were found to be associated with many diseases and the alternation concentrations of endogenous biothiols in cellular and organs have gradually been considered as essential biomarkers of some common clinical diseases, including osteoporosis, liver damages, and even severe cancers. ${ }^{6-8}$ Specifically, the normal intracellular levels of Cys was found to be in the range of $30-200 \mu \mathrm{M}{ }^{9}$ The deficiency of Cys may lead to hair depigmentation, skin lesions, and metabolic disorders, while the over-expressed of Cys in bodies is associated with oxidative DNA damage. ${ }^{10}$ Appropriate amounts of Hcy, which is the precursor of Cys in vivo, were always 15-20 times lower than that of Cys. ${ }^{11}$ Its deficiency or redundancy will cause birth defects, folate deficiencies, and even cognitive impairment for old people. ${ }^{11-13}$ Compared with the first two kinds of biothiols, GSH is the most abundant intracellular nonprotein thiol in vivo (1-10 mM). ${ }^{14}$ As the significance of these biothiols, it is highly demanded to develop robust bioanalytical methods to detect and monitor biothiols in biological samples for further understanding the functionality and potential use in clinical diagnosis of these species.

Regarding to the detection of biothiols, some methods have been developed, including high-performance liquid chromatography (HPLC), capillary electrophoresis, mass spectrometry (MS) and fluorescence technique. ${ }^{15-21}$ Among them, fluorescent method has been proved to be a desirable tool for in situ biomolecule visualization and 
detection owing to its simplicity and real-time detection..$^{22-25}$ To date, a large number of fluorescence probes for the detection of biothiols have been reported in the past few years based on various sensing mechanisms: (1) -SH cleavage reactions; (2) - $\mathrm{SH}$ nucleophilic reaction; (3) metal-complexes displacement strategies and others. ${ }^{6,26-29}$ Nevertheless, works that contributed to detect of biothiols from cells to live animals to elucidate the distribution and functions of biothiols are still limited.

$<$ Scheme $1>$

In this presented work, we reported a red-emission fluorescence probe (DC) for the detection of biothiols in vitro and in vivo. DC was synthesized by a condensation reaction of 3-formyl-N-ethylcarbazole and 2-(3-cyano-4,5,5-trimethyl-5Hfuran-2-ylidene) malononitrile in methanol (Scheme 1A). DC was designed with a donor- $\pi-$ acceptor $(\mathrm{D}-\pi-\mathrm{A})$ structure, in which 3-formyl-N-ethylcarbazole served as the electron donor group (EDG), while 2-(3-cyano-4,5,5-trimethyl-5H-furan-2-ylidene) malononitrile displayed an electron withdrawing group (EWG). Under this design strategy, an intramolecular charge transfer (ICT) process was achieved inside DC and this probe exhibited red fluorescence. Through nucleophilic addition of three different bilthiols (Cys, Hcy and GSH), the $\mathrm{C}=\mathrm{C}$ double bond between $\mathrm{EDG}$ and $\mathrm{EWG}$ was attacked and the large conjugation system was thereby destructed, resulting in the fluorescence quenching of DC (Scheme 1B). DC was found to be able to fast response to biothiols with high selectivity and sensitivity. Finally, DC was applied to detect of endogenous and exogenous biothiols in live cells and animals.

\section{Experimental}

\section{Materials and instruments}

3-Formyl-N-ethylcarbazole was purchased from Aladdin reagent Co. (Shanghai, China). Piperidine, metal ions (nitrate salts), anions (sodium salts) and three kinds of 
biothiols (Cys, Hcy, and GSH) were obtained from Sinopharm Chemical Reagent Co., Ltd. (China). All the experimental live zebrafish and nude mice were obtained from the Experimental Animal Center of Dalian Medical University and the experiments were performed in compliance with the relevant laws and guidelines. Unless otherwise stated, solvents and reagents were of analytical grade from commercial suppliers and were used without further purification.

${ }^{1} \mathrm{HNMR}$ and ${ }^{13} \mathrm{CNMR}$ spectra were recorded with a BRUKER AVANCE 400 MHZ spectrometer with chemical shifts reported as ppm (in DMSO- $d_{6}$, TMS as internal standard). Coupling constants ( $J$ values) are reported in hertz. API mass spectra were recorded on an Agilent 6530 QTOF spectrometer. Absorption spectra were measured with a Perkin Elmer Lambda 900 UV/VIS/NIR spectrophotometer (USA). Fluorescence spectra were measured with Perkin Elmer LS55 luminescence spectrometer (USA). All pH measurements were made with an OHAUS Starter 3100/f meter (USA). Fluorescent live cell images were recorded on a Nikon A1 inverted confocal laser-scanning microscope. Biothiols in adult zebrafish and mice were imaged by a SPECTRAL Ami Imaging Systems (Spectral Instruments Imaging, LLC, Tucson, AZ) with an excitation filter $465 \mathrm{~nm}$ and an emission filter $610 \mathrm{~nm}$. Amiview Analysis software (Version 1.7.06) was used to calculate fluorescence intensity on region of interest (ROI), and values are presented as the mean $\pm \mathrm{SD}$ for each group of three experiments.

Synthesis of $\boldsymbol{D C}$

2-(3-cyano-4,5,5-trimethyl-5H-furan- 2-ylidene) malononitrile was synthesized according to the reported literature. ${ }^{30}$

3-Formyl-N-ethylcarbazole $(0.223 \mathrm{~g}, 1 \mathrm{mmol})$ was dissolved into $20 \mathrm{~mL}$ methanol, followed by the addition of the solution of 2-(3-cyano-4,5,5-trimethyl-5H-furan2-ylidene) malononitrile $(0.199 \mathrm{~g}, 1 \mathrm{mmol})$ and a catalytic amount of piperidine in 20 
$\mathrm{mL}$ methanol. The reaction mixture was then refluxed $6 \mathrm{~h}$ to form a dark precipitate. After a filtration, 3-time cool methanol rinse and vacuum drying, DC was obtained as a wine-colored solid. Yield, 82\%. ${ }^{1} \mathrm{H}$ NMR (400 MHz, DMSO- $\left.d_{6}\right): \delta(p p m) 8.81(\mathrm{~s}, 1 \mathrm{H})$, $8.28(\mathrm{~d}, J=6.16 \mathrm{~Hz}, 1 \mathrm{H}), 8.20(\mathrm{~d}, J=12.96 \mathrm{~Hz}, 1 \mathrm{H}), 8.08(\mathrm{~d}, J=6.72 \mathrm{~Hz}, 1 \mathrm{H}), 7.77(\mathrm{~d}$, $J=6.92 \mathrm{~Hz}, 1 \mathrm{H}), 7.71(\mathrm{~d}, J=6.48 \mathrm{~Hz}, 1 \mathrm{H}), 7.55(\mathrm{t}, J=6.92 \mathrm{~Hz}, 1 \mathrm{H}), 7.32(\mathrm{t}, J=5.98$ $\mathrm{Hz}, 1 \mathrm{H}), 7.28(\mathrm{~d}, J=12.96 \mathrm{~Hz}, 1 \mathrm{H}), 4.52(\mathrm{q}, J=5.60 \mathrm{~Hz}, 2 \mathrm{H}), 1.85(\mathrm{~s}, 6 \mathrm{H}), 1.36(\mathrm{t}, J=$ $5.48 \mathrm{~Hz}, 3 \mathrm{H}) .{ }^{13} \mathrm{C}$ NMR $\left(101 \mathrm{~Hz}, \mathrm{DMSO}-d_{6}\right), \delta(p p m) 177.8,176.3,150.4,148.2,142.9$, $141.3,140.8,134.4,128.3,127.3,126.1,122.8,121.4,120.8,119.4,113.5,112.7,111.9$, 110.7, 102.0, 99.5, 96.4, 37.9, 25.9, 14.3. ESI-MS (positive mode, $\mathrm{m} / \mathrm{z}$ ) calcd for $\mathrm{C}_{26} \mathrm{H}_{20} \mathrm{~N}_{4} \mathrm{O}^{+}: 405.16370$, found: $405.17196[\mathbf{D C}+\mathrm{H}]^{+}$.

General procedures of spectra detection

A stock solution of DC was prepared in dimethyl sulfoxide (DMSO) at the concentration of $0.5 \mathrm{mM}$. Prior spectroscopic measurements, the solution was freshly prepared by diluting the stock solution to corresponding HEPES buffer solution at the concentration of $10 \mu \mathrm{M}$ (DMSO: $\mathrm{H}_{2} \mathrm{O}=3: 7,20 \mathrm{mM}, \mathrm{pH}=7.4$ ). Solutions of a series of anions, reactive oxygen species and biomolecules $(20 \mathrm{mM})$ were freshly prepared by dissolving corresponding chemicals in deionized water. ${ }^{31}$ For spectroscopic analysis of biothiols, biothiols at different concentrations were added into the DC solution (total volume $3 \mathrm{~mL}$ ), followed by the spectroscopic measurements immediately. Fluorescence slits are $10 \mathrm{~nm}, 10 \mathrm{~nm}$ at $625 \mathrm{~nm}$ emission.

Fluorescence imaging of biothiols in live A549 cells

For cell imaging, live A549 cells were detached, transplanted onto 12-well plates with glass-bottoms, and cultured for $24 \mathrm{~h}$ before imaging. Then, A549 cells were washed for three times with PBS and incubated with DC $(10 \mu \mathrm{M}$, in PBS buffer containing $~ 1 \%$ DMSO as the co-solvent) in serum-free medium at $37^{\circ} \mathrm{C}$ for $0.5 \mathrm{~h}$ in a $\mathrm{CO}_{2}$ incubator. 
The cells were washed with PBS for another three times prior to confocal microscopic imaging. For the biothiol-blocking group, the A549 cells were pretreated with N-ethylmaleimide (NEM, one type of sulfhydryl-blocking reagents) at $1 \mathrm{mM}$ in serum-free medium at $37{ }^{\circ} \mathrm{C}$ for $0.5 \mathrm{~h}$, washed with PBS for three times, then incubated with $10 \mu \mathrm{M}$ DC in serum-free medium at $37^{\circ} \mathrm{C}$ for another $0.5 \mathrm{~h}$, and washed with PBS for another three times prior to confocal microscopic imaging. For the Cys or GSH recovering group, after being pre-treated with ENM at the same condition, A549 cells were then incubated with DC $(10 \mu \mathrm{M})$, and finally incubated with Cys $(60 \mu \mathrm{M})$ and GSH $(60 \mu \mathrm{M})$ for another 0.5 h. Then, A549 cells were washed with PBS buffer for three times before subjecting to microscope imaging. Al the A549 cells were imaged using an excitation filter $(465 \mathrm{~nm})$ and an emission filter $(610 \mathrm{~nm})$. Scale bar $=30 \mu \mathrm{m}$.

Fluorescence imaging of biothiols in live adult zebrafish

Adult zebrafish were immersed into PBS solution with $50 \mu \mathrm{M}, 100 \mu \mathrm{M}$ and $500 \mu \mathrm{M}$ of N-ethylmaleimide (NEM) for 30 min to eliminate the influence of endogenous biothiols at different levels. Subsequently, the pre-treated zebrafish were further incubated with DC (10 $\mu \mathrm{M}$, in PBS buffer containing 5\% DMSO as the co-solvent) for 7 min. Images of above treated zebrafish were taken under Ami Imaging System using an excitation filter $(465 \mathrm{~nm})$ and an emission filter $(610 \mathrm{~nm})$, with untreated zebrafish using as control group.

Fluorescence imaging of biothiols in live nude mice

The nude mice (6-8 weeks old) were anesthetized by isoflurane with a flow of oxygen during all of the experiments. For fluorescence imaging of endogenous biothiols in living mice, the left leg of mouse was subcutaneously injected of NEM (50 $\mu \mathrm{L} 10 \mathrm{mM}$ ) to eliminate endogenous biothiols for $30 \mathrm{~min}$. While, the right leg injected of PBS (50 $\mu \mathrm{L}, 20 \mathrm{mM})$ as the control group. Then, DC $(10 \mu \mathrm{M}, 125 \mu \mathrm{L}$, in PBS buffer containing 
$5 \%$ DMSO as the co-solvent) was injected into the left and right legs of mouse, respectively.

For fluorescence imaging of exogenous biothiols in living mice, NEM (50 $\mu \mathrm{L} 10 \mathrm{mM})$ was firstly injected into the left leg and right leg areas of interest for $30 \mathrm{~min}$. Then, DC $(10 \mu \mathrm{M}, 125 \mu \mathrm{L}$, in PBS buffer containing 5\% DMSO as the co-solvent) was injected into the left and right legs of mouse, followed by the injection of Cys (10 $\mu \mathrm{M}, 125 \mu \mathrm{L})$ and GSH $(10 \mu \mathrm{M}, 125 \mu \mathrm{L})$ into the left legs of mouse.

The images were then recorded under Ami Imaging System at different times using an excitation filter $(465 \mathrm{~nm})$ and an emission filter $(610 \mathrm{~nm})$.

\section{Results and Discussion}

$U V$-vis responses of $D C$ to biothiols

$<$ Fig. 1 $>$

The sensing ability of DC towards various biological related reactive species was first investigated by UV-vis spectra in HEPES buffer $\left(20 \mathrm{mM}, \mathrm{pH}=7.4,70 \% \mathrm{H}_{2} \mathrm{O}\right)$. As shown in Fig. 1A, free DC displayed a strong peak maximum at $513 \mathrm{~nm}$. Upon addition of Cys, Hcy and GSH, the absorbance intensities at $513 \mathrm{~nm}$ were gradually decreased and the new absorption peak at $340 \mathrm{~nm}$ emerged. However, other species, including $\mathrm{HSO}_{3}{ }^{-}, \mathrm{HSO}_{4}^{-}, \mathrm{HCO}_{3}^{-}, \mathrm{NO}_{2}^{-}, \mathrm{NO}_{3}{ }^{-},{ }^{1} \mathrm{O}_{2}, \mathrm{OH}^{-}, \mathrm{ONOO}^{-}, \mathrm{P}_{2} \mathrm{O}_{7}{ }^{4-}, \mathrm{PO}_{4}{ }^{2-}, \mathrm{SO}_{3}{ }^{2-}, \mathrm{SO}_{4}{ }^{2-}, \mathrm{Pi}$, $\mathrm{F}^{-}, \mathrm{Cl}^{-}, \mathrm{Br}^{-}, \mathrm{AcO}^{-}, \mathrm{ClO}^{-}$, and $\mathrm{H}_{2} \mathrm{PO}_{3}^{-}$, induced no responses or weak response $\left(\mathrm{S}^{2-}\right)$. Meanwhile, the solution color of DC changed from pink to colorless (Fig. 1B), allowing DC to be used a convenient tool for "naked-eye" detection of biothiols.

In the presence of different concentrations of biothols, changes of UV-vis spectra were then investigated. As shown in Fig. 2A-2C, free DC displayed a strong absorption at $513 \mathrm{~nm}$. Upon addition of increasing concentrations of Cys, Hcy and GSH (0-100 $\mu \mathrm{M})$, DC's absorbance at $513 \mathrm{~nm}$ were gradually decreased and the absorbance at 340 
nm were increased at the same time. The recognition effects among three biothiols on DC exhibited nearly no differences. Moreover, when the amounts of the biothiols come to $60 \mu \mathrm{M}$, the titration equilibrium was finally achieved and no further absorption spectra change can be found with more addition of biothiols (Fig. 2D).

$<$ Fig. 2>

Fluorescence responses of $\boldsymbol{D C}$ to biothiols

$<$ Fig. 3 $>$

Followed by the UV-vis spectra analysis, fluorescence responses of DC to biothiols were studied. As shown in Fig. S4, only small fluctuations was found in fluorescence intensity of DC at $625 \mathrm{~nm}$ within $35 \mathrm{~h}$, suggesting the high stability of DC in aqueous solution. Then, fluorescence selectivity and titration experiments were conducted, respectively. As shown in Fig. 3A, DC displayed an obvious emission peak at $625 \mathrm{~nm}$ in HEPES aqueous buffer (DMSO: HEPES=3:7, $20 \mathrm{mM}, \mathrm{pH}=7.4$ ). In the presence of Hcy, Cys and GSH, the fluorescence emission of DC were found to be significantly quenched. The emission was negligibly changed upon the addition of $\mathrm{S}^{2-}$. In contrast, no obvious changes in emission spectra caused by other competitive species, including $\mathrm{HSO}_{3}{ }^{-}, \mathrm{HSO}_{4}{ }^{-}, \mathrm{HCO}_{3}{ }^{-}, \mathrm{NO}_{2}{ }^{-}, \mathrm{NO}_{3}{ }^{-},{ }^{1} \mathrm{O}_{2}, \mathrm{OH}^{-}, \mathrm{ONOO}^{-}, \mathrm{P}_{2} \mathrm{O}_{7}{ }^{4-}, \mathrm{PO}_{4}{ }^{2-}, \mathrm{SO}_{3}{ }^{2-}$, $\mathrm{SO}_{4}{ }^{2-}, \mathrm{Pi}, \mathrm{F}^{-}, \mathrm{Cl}^{-}, \mathrm{Br}^{-}, \mathrm{AcO}^{-}, \mathrm{ClO}^{-}$and $\mathrm{H}_{2} \mathrm{PO}_{3}{ }^{-}$. Furthermore, red fluorescence colour of DC disappeared exclusively in the presence of Hcy, Cys and GSH (Fig. 3B). The results indicate that DC can be employed as a specific fluorescent probe for the detection of Hcy, Cys and GSH.

$<$ Fig. $4>$

The fluorescence responses of DC to biothiols were further investigated by recording the changes of emission spectra in the presence of Hcy, Cys and GSH in HEPES buffer. As shown in Fig. 4A-4C, responses of DC to biothiols led to more than 
$85 \%$ quenching of the emissions at $625 \mathrm{~nm}$, which could be attributed to the breakage of DC's $\pi$-conjugation after the nucleophilic addition reaction between the $\mathrm{C}=\mathrm{C}$ bond and the -SH of biothiols. ${ }^{32}$ In consistence with the fluorescence quenching effect, the fluorescence intensity of DC dropped gradually when three biothiols were added to the solution of DC and the fluorescence intensities became constant when the amount of biothiols was above to $60 \mu \mathrm{M}$ (Fig. 4D). In addition, this decrease trend of fluorescence was linearly with the concentrations of three biothiols (Fig. S5). According to IUPAC criteria $(\mathrm{LOD}=3 \sigma / \mathrm{k}),{ }^{33}$ the detection limits (LOD) of DC for Hcy, Cys and GSH were calculated to be $0.26,0.43$, and $0.44 \mu \mathrm{M}$, respectively.

Sensing mechanism study

The reaction mechanism between DC and biothiols was confirmed by high resolution mass spectrometry (HRMS) analysis. As shown in Fig. S3, the molecular ion peak at $\mathrm{m} / \mathrm{z} 405.17196$ can be assigned to the peak of $[\mathbf{D C}+\mathrm{H}]^{+}$(calcd. $\mathrm{m} / \mathrm{z} 405.1715$ ). After reaction of DC with Cys, a new peak at m/z 526.1920 was obtained in the reaction mixture (Fig. S6), which agreed well with the molecular ion peak of the Cys-involved nucleophilic addition product (calcd. m/z 526.1913). Similarly, upon the addition of Hcy, a new peak assigned to the corresponding nucleophilic addition product at $\mathrm{m} / \mathrm{z} 540.2079$ was emerged (calcd. m/z 540.2069) (Fig. S7). The results indicated that the nucleophilic addition reaction between the $\mathrm{C}=\mathrm{C}$ double bond of $\mathrm{DC}$ with sulfhydryl group (-SH) of biothiols is responsible for the sensing mechanism of DC towards biothiols. We also try our best to find the molecular ion peak of GSH-addition product by HRMS analysis, but failed.

Time/pH dependent fluorescence responses of $\boldsymbol{D C}$ to biothiols

$<$ Fig. 5 $>$

Time-dependent fluorescence spectra of DC with respect to Cys, Hcy and GSH 
were studied. In HEPES buffer solution, the fluorescence intensities of DC at $625 \mathrm{~nm}$ were recorded consistently in the absence and in the presence of various amounts of three biothiols. Fig. 5A indicated that the nucleophilic addition reaction between DC and Cys $(10 \mu \mathrm{M}, 30 \mu \mathrm{M}$ and $50 \mu \mathrm{M}$, respectively) could be finalized within $1 \mathrm{~min}$. The fluorescence intensities change of DC in response to Hcy and GSH were similar, but the nucleophilic addition process would cause more time ( $2 \mathrm{~min}$ and $4 \mathrm{~min}$, respectively) (Fig. 5B, 5C). Overall, DC displayed a rapid response for biothiols, enabling it to rapidly detect of biothiols in biological systems. ${ }^{34-37}$

In addition, the sensing ability of DC towards Cys, Hcy and GSH was further investigated under various $\mathrm{pH}$ values, respectively. As shown in Fig. 5D, strong fluorescence emission of DC can be observed at $625 \mathrm{~nm}$ in the $\mathrm{pH}$ range of 3.0-10.5, while the fluorescence would be quenched to a very weak level in the presence of 60 $\mu \mathrm{M}$ different kinds of biothiols (Cys, Hcy and GSH) in the $\mathrm{pH}$ range of 4.0-10.5. These results indicated that DC can be used for the detection of biothiols under physiological conditions

Fluorescence imaging of exogenous and endogenous biothiols in cells

Encouraged by the above-mentioned excellent properties of DC in the detection of three biothiols species, the application of DC was evaluated in the detection of exogenous and endogenous biothiols in live cells by fluorescence imaging. Firstly, the cytotoxicity of DC has been examined on A549 cells by MTT assay. ${ }^{38}$ As shown in Fig. S8, 91\% of A549 cells were still alive after incubation with up to $10 \mu \mathrm{M} \mathrm{DC}$ for $24 \mathrm{~h}$ and the cell viability remained $85 \%$ at a higher concentration of DC $(40 \mu \mathrm{M})$ after $24 \mathrm{~h}$ incubation. The result demonstrated that DC could be used to detect of intracellular biothiols with acceptable cytotoxicity.

$<$ Fig. 6> 
Then, the fluorescence imaging of endogenous and exogenous biothiols in live cells was examined by confocal laser scanning microscopy. As shown in Fig. 6(a-c), the A549 cells incubated with DC displayed silent fluorescence emission during microscopy when excited with a $465 \mathrm{~nm}$ laser, indicated that DC reacted with endogenous biothiols in live cells. However, after pre-treatment with N-ethylmaleimide (NEM) to eliminate endogenous biothiols, the cells showed intense red emission after further incubation with DC. In addition, upon incubation of NEM-pretreated cells with exogenous Cys and GSH, quenched fluorescence was observed again for Cys and GSH (Fig. 6(d-1)). Since Hcy is hardly detectable in healthy mammalian cell, ${ }^{39}$ thus fluorescence imaging of exogenous Hcy was omitted. The results indicated that DC could be used to detect of exogenous and endogenous biothiols in live cells.

Fluorescence imaging of exogenous and endogenous biothiols in live animals

Inspired by the successful application of DC in the detection of endogenous and exogenous biothiols in live cells, we then subsequently explored the feasibility of DC for visualizing biothiols in living animals. The capability of DC was firstly evaluated in adult zebrafish because of their highly homologous genes to human beings. Herein, blank zebrafish, which displayed no fluorescence, was selected as the control group (Fig. S9(A)a). Due to the endogenous produced biothiols in zebrafish, silent fluorescence was found even the zebrafish was pre-treated with probe DC. In order to further to confirm that DC can detect of biothiols in zebrafish, we used sulfhydryl-specific scavenger NEM to eliminate the influence of endogenous biothiols in zebrafish before further incubating zebrafish with DC. Zebrafish exhibited different fluorescence intensities from weak to strong when these zebrafish were treated with different amounts of NEM (from $50 \mu \mathrm{M}$ to $500 \mu \mathrm{M}$ ). Fig. S9(B) depicted the average fluorescence intensity of interest regions of adult zebrafish. 
$<$ Fig. $7>$

Similar experiments were also conducted in nude mice. Herein, the fluorescence responses of DC towards endogenous and exogenous biothiols in mice were discussed respectively. Firstly, NEM was injected into the left leg of mouse to eliminate the influence of endogenous-produced biothiols. By comparison, the same amount of PBS was injected into the right leg. Then, $10 \mu \mathrm{M}$ DC was injected into the left leg and right leg of mouse, respectively. Images were then taken in a continuous period from $10 \mathrm{~min}$ to 40 min. As shown in Fig. 7(A), the left leg which has eliminated endogenous-produced biothiols by NEM displayed significant fluorescence, while no obvious fluorescence can be detected in the right leg when the influence of endogenous biothiols existed. Fig. 7(B) depicted the average fluorescence intensity of interest regions of left leg and right leg.

$<$ Fig. $8>$

$<$ Fig. 9>

To further prove that DC could visualize exogenous biothiols, we injected NEM $(50 \mu \mathrm{L} 10 \mathrm{mM})$ into both legs of mouse to scavenge biothiols at interest regions, followed by the injection of DC $(10 \mu \mathrm{M}, 125 \mu \mathrm{L})$ into the same region of both legs. Subsequently, Cys (125 $\mu \mathrm{L} 10 \mu \mathrm{M})$ was injected to the left leg. As shown in Fig. 8(A), legs treated with Cys remained non-fluorescence, but the right legs which were treated with DC only exhibited a fluorescence turn-on trend along with time. Moreover, similar trend was also observed when Cys was replaced by GSH in this experiment (Fig. 9(A). Fig. 8(B) and Fig. 9(B) depicted the average fluorescence intensity of interest regions of left leg and right leg. All of these experiments indicated that DC could be utilized as an excellent tool in detecting biothiols in vivo. 


\section{Conclusions}

In summary, a red-emission fluorescence probe $\mathbf{D C}$ was designed and developed for the selective and sensitive detection of three important biothiols (Cys, Hcy and GSH). The -SH of biothiols reacted with the $\mathrm{C}=\mathrm{C}$ bond of $\mathbf{D C}$ to break of the $\pi$-conjugation, resulting in the obvious fluorescence quenching. The nucleophilic addition reaction mechanism between DC and biothiols has been verified by HRMS analysis and spectroscopic titration studies. The red fluorescence of DC exclusively quenched in the presence of biothiols over other bioactive species. DC exhibits excellent performance such as high stability, fast response time, reliability at physiological $\mathrm{pH}$ and low cytotoxicity. Confocal microscopic imaging studies demonstrated its usage for the monitoring endogenous and exogenous biothiols in live cells. DC presents high optical penetration in tissue and has been successfully demonstrated the application in the detection of endogenous and exogenous biothiols in live animals. It is expected that this work enabled the monitoring of biothiols dynamics and transportations in live animals to expand the understanding of physiological and pathological roles of biothiols in clinical practices. Although DC shows fluorescence quenching response toward biothiols lowing the application value to a certain extent, the development of 'OFF-ON' or 'turn-ON' types of fluorescence probes for biothiols and other bioactive species is actively being carried out in our research team.

\section{Acknowledgements}

This work was supported by the Talent Program-Outstanding Youth Science Project, Liaoning (No. XLYC1807199), the Distinguished Professor Program of Liaoning (XLYC1802074), the "Seeding Raising" Project of Young Scientific and Technological Talents of Liaoning Provincial Department of Education (2019LNQN03; 2019LNJC18), and the Youth Fund of University of Science and Technology Liaoning (2018QN02). 


\section{References}

[1] B. Gao, L. Cui, Y. Pan, G. Zhang, Y. Zhou, C. Zhang, S. Shuang, and Dong C. RSC Adv., 2016, 6, 43028.

[2] J. S. Lan, R. F. Zeng, Y. Liu, Y. W. Xiang, X. Y. Jiang, L. Liu, S. S. Xie, Y. Ding, and T. Zhang, Analyst, 2019, 144, 3676.

[3] X. Chen, Y. Zhou, X. Peng, and J. Yoon, Chem Soc Rev., 2010, 39, 2120.

[4] X. Xia, Y. Qian, and B. Shen, J. Mater. Chem. B, 2018, 6, 3023.

[5] Y. Cao, J. Liu, L. Zou, B. Ye, and G. Li, Anal. Chim. Acta, 2021, 1145, 46.

[6] Y. Hu, C. H. Heo, G. Kim, E. J. Jun, J. Yin, H. M. Kim, and J. Yoon, Anal. Chem., 2015, 87,3308 .

[7] Z. H. Fu, X. Han, Y. Shao, J. Fang, Z. H. Zhang, Y. W. Wang, and Y. Peng, Anal. Chem., 2017, 89, 1937.

[8] L. Y. Niu, Y. Z. Chen, H. R. Zheng, L. Z. Wu, C. H. Tung, and Q. Z. Yang, Chem. Soc. Rev., 2015, 44, 6143.

[9] Y. Yue, F. Huo, P. Ning, Y. Zhang, J. Chao, X. Meng, and C. Yin, J. Am. Chem. Soc., 2017, 139, 3181.

[10] S. Feng, Y. Fang, W. Feng, Q. Xia, and G. Feng, Dyes and Pigments, 2017, 146, 103.

[11] J. Zheng, J. Li, H. Luo, L. Sun, M. Sang, and X. Yu, RSC Adv., 2021, 11, 4356.

[12] W. Zhang, H. Zhang, M. Wang, P. Li, P. C. Ding, W. Zhang, H. Wang, and B. Tang, Anal. Chem., 2020, 92, 16221.

[13] Y. Yue, F. Huo, Y. Wang, K. Ma, X. Li, and C. Yin, Chem. Commun., 2020, 56, 9146.

[14] P. Hu, Y. Zhang, D. Wang, G. Qi, and Y. Jin, Anal. Chem., 2021, 93, 4240.

[15] J. Vacek, B. Klejdus, J. Petrlova, L. Lojkova, and V. Kuban, Analyst, 2006, 131, 
1167.

[16] T. Inoue, and J. R. Kirchhoff, Anal. Chem., 2002, 74, 1349.

[17] N. Burford, M. D. Eelman, D. E. Mahony, and M. Morash, Chem. Commun., 2003, 146.

[18] R. F. Zeng, J. S. Lan, T. Wu, L. Liu, Y. Liu, R. J. Y. Ho, Y. Ding, and T. Zhang, Food Chem., 2020, 318, 126358.

[19] A. S. K. Kumar, W. B. Tseng, M. J. Wu, Y. Y. Huang, and W. L. Tseng, Anal. Chim. Acta, 2020, 1113, 43 .

[20] Y. Zou, M. Li, Y. Xing, T. Duan, X. Zhou, and F. Yu, ACS Sens., 2020, 5, 242.

[21] S. Lee, J. Li, X. Zhou, J. Yin, and J. Yoon, Coord. Chem. Rev., 2018, 366, 29.

[22] Q. Hu, C. Yu, X. Xia, F. Zeng, and S. Wu, Biosens. Bioelectron., 2016, 81, 341.

[23] H. Feng, Z. Zhang, Q. Meng, H. Jia, Y. Wang, and R. Zhang, Adv. Sci., 2018, 5, 1800397.

[24] W. Wan, Y. Huang, Q. Xia, Y. Bai, Y. Chen, W. Jin, M. Wang, D. Shen, H. Lyu, Y. Tang, X. Dong, Z. Gao, Q. Zhao, L. Zhang, and Y. Liu, Angew. Chem. Int. Ed., 2021, 60, 11335.

[25] W. Wan, W. Jin, Y. Huang, Q. Xia, Y. Bai, H. Lyu, D. Liu, X. Dong, W. Li, and Y. Liu, Anal. Chem., 2021, 93, 1717.

[26] Z. Xu, T. Qin, X. Zhou, L. Wang, and B. Liu, Trends Anal. Chem., 2019, 121, 115672.

[27] W. Liu, J. Chen, and Z. Xu, Coord. Chem. Rev., 2021, 429, 213638.

[28] Y. F. Kang, L. Y. Niu, and Q. Z. Yang, Chin. Chem. Lett., 2019, 30, 1791.

[29] N. Kaur, S. Chopra, G. Singh, P. Raj, A. Bhasin, S. K. Sahoo, A. Kuwar, and N. Sing, J. Mater. Chem. B, 2018, 6, 4872.

[30] M.-Y. Wu, K. Li, C.-Y. Li, J.-T. Hou, and X.-Q. Yu, Chem. Commun., 2014, 50, 
183.

[31] H. Feng, Y. Wang, J. Liu, Z. Zhang, X. Yang, R. Chen, Q. Meng, and R. Zhang, J. Mater. Chem. B, 2019, 7, 3909.

[32] K. Xiong, F. Huo, J. Chao, Y. Zhang, and C. Yin, Anal. Chem., 2019, 91, 1472.

[33] C. Liu, R. Zhang, W. Zhang, J. Liu, Y. L. Wang, Z. Du, B. Song, Z. P. Xu, and J. L. Yuan, J. Am. Chem. Soc., 2019, 141, 8462.

[34] F. Liu, S. Zang, J. Jing, and X. Zhang, Anal. Methods, 2020, 12, 3797.

[35] Y. L. Fu, X. G. Chen, H. Li, W. Feng, and Q. H. Song, New J. Chem., 2020, 44, 13781

[36] S. Chakraborty, M. M. Joseph, S. Varughese, S. Ghosh, K. K. Maiti, A. Samanta, and A. Ajayaghosh, Chem. Sci., 2020, 11, 12695.

[37] H. Zhang, L. Xu, W. Chen, J. Huang, C. Huang, J. Sheng, and X. Song, ACS Sens., 2018, 3, 2513.

[38] L. Zhang, D. Duan, Y. Liu, C. Ge, X. Cui, J. Sun, and J. Fang, J. Am. Chem. Soc., 2014, 136, 226.

[39] Q. Miao, Q. Li, Q. Yuan, L. Li, Z. Hai, S. Liu, and G. Liang, Anal. Chem., 2015, 87, 3460. 


\section{Figure Captions}

Scheme 1 Schematic illustration the design of fluorescence probe DC for biothols sensing. (A) Synthetic procedure of DC. (B) The proposed sensing mechanism of DC towards biothiols.

Fig. 1 UV-vis responses of DC to biothols. (A) UV-vis absorption spectra of DC (10 $\mu \mathrm{M}$ ) in HEPES aqueous buffer (DMSO: HEPES=3:7, $20 \mathrm{mM}, \mathrm{pH}=7.4$ ) in the presence of various analytes $(60 \mu \mathrm{M})$. (B) Colorimetric changes of DC $(10 \mu \mathrm{M})$ in the presence of various analytes (60 $\mu \mathrm{M})$ : (1) Free DC, (2) Cys, (3) Hcy, (4) GSH, (5) $\mathrm{S}^{2-}$, (6) $\mathrm{HSO}_{3}{ }^{-}$,

(7) $\mathrm{HSO}_{4}^{-}$, (8) $\mathrm{HCO}_{3}^{-}$, (9) $\mathrm{NO}_{2}^{-}$, (10) $\mathrm{NO}_{3}^{-}$, (11) ${ }^{1} \mathrm{O}_{2}$, (12) $\mathrm{OH}^{-}$, (13) $\mathrm{ONOO}^{-}$, (14) $\mathrm{P}_{2} \mathrm{O}_{7}{ }^{4-},(15) \mathrm{PO}_{4}{ }^{2-}$, (16) $\mathrm{SO}_{3}{ }^{2-}$, (17) $\mathrm{SO}_{4}{ }^{2-}$, (18) $\mathrm{Pi}$, (19) $\mathrm{F}^{-}$, (20) $\mathrm{Cl}^{-}$, (21) $\mathrm{Br}^{-}$, (22) $\mathrm{AcO}^{-}$, (23) $\mathrm{ClO}^{-}$and (24) $\mathrm{H}_{2} \mathrm{PO}_{3}^{-}$.

Fig. 2 UV-vis absorption spectra of DC $(10 \mu \mathrm{M})$ in the presence of $0-100 \mu \mathrm{M}$ (A) Cys, (B) Hcy and (C) GSH in HEPES aqueous buffer (DMSO:HEPES=3:7, $20 \mathrm{mM}, \mathrm{pH}=7.4$ ). (D) Absorbances of DC at $513 \mathrm{~nm}$ as a function of biothiols concentrations

Fig. 3 Fluorescence responses of DC to biothols. (A) Fluorescence responses of DC (10 $\mu \mathrm{M})$ to various analytes $(60 \mu \mathrm{M})$ in HEPES aqueous buffer (DMSO: HEPES=3:7, 20 $\mathrm{mM}, \mathrm{pH}=7.4$ ). Excitation was performed at $513 \mathrm{~nm}$. (B) Fluorescence color images of DC $(10 \mu \mathrm{M})$ in HEPES aqueous buffer (DMSO:HEPES=3:7, $20 \mathrm{mM}, \mathrm{pH}=7.4)$ in the presence of various analytes (60 $\mu \mathrm{M})$ under UV light: (1) Free DC, (2) Cys, (3) Hcy, (4) GSH, (5) $\mathrm{S}^{2-}$, (6) $\mathrm{HSO}_{3}^{-}$, (7) $\mathrm{HSO}_{4}^{-},(8) \mathrm{HCO}_{3}^{-}$, (9) $\mathrm{NO}_{2}^{-}$, (10) $\mathrm{NO}_{3}^{-}$, (11) ${ }^{1} \mathrm{O}_{2}$, (12) $\mathrm{OH}^{-}$, (13) $\mathrm{ONOO}^{-}$, (14) $\mathrm{P}_{2} \mathrm{O}_{7}^{4-}$, (15) $\mathrm{PO}_{4}{ }^{2-}$, (16) $\mathrm{SO}_{3}{ }^{2-}$, (17) $\mathrm{SO}_{4}{ }^{2-}$, (18) $\mathrm{Pi}$, (19) $\mathrm{F}^{-}$, (20) $\mathrm{Cl}^{-}$, (21) $\mathrm{Br}^{-}$, (22) $\mathrm{AcO}^{-}$. (23) $\mathrm{ClO}^{-}$and (24) $\mathrm{H}_{2} \mathrm{PO}_{3}^{-}$.

Fig. 4 Fluorescence spectra of DC $(10 \mu \mathrm{M})$ in the presence of different amounts $(0-100$ $\mu \mathrm{M}$ ) of (A) Cys, (B) Hcy and (C) GSH in HEPES aqueous buffer (DMSO:HEPES=3:7, $20 \mathrm{mM}, \mathrm{pH}=7.4$ ). (D) Fluorescence intensities of $\mathbf{D C}$ at $625 \mathrm{~nm}$ against the 
concentrations of Cys, Hcy and GSH. Excitation was performed at $513 \mathrm{~nm}$.

Fig. 5 Time scan fluorometry of DC $(10 \mu \mathrm{M})$ the addition of (A) Cys, (B) Hcy and (C) GSH in PBS aqueous buffer (DMSO: HEPES=3:7, $20 \mathrm{mM}, \mathrm{pH}=7.4)$. (घ) $0 \mu \mathrm{M},(\diamond) 10$ $\mu \mathrm{M},(\boldsymbol{\Delta}) 30 \mu \mathrm{M}$ and ( $\mathbf{\nabla}) 50 \mu \mathrm{M}$ of biothiols added, respectively. (D) Influence of $\mathrm{pH}$ on the fluorescence intensities of DC in the absence and presence of Cys, Hcy and GSH $(60 \mu \mathrm{M})$, respectively. The intensities were recorded at $625 \mathrm{~nm}$, excitation was performed at $513 \mathrm{~nm}$.

Fig. 6 Fluorescence imaging of biothiols in live A549 cells. (a-c) A549 cells treated with DC (10 $\mu \mathrm{M}, 10 \mu \mathrm{M}$ in PBS buffer containing $\approx 1 \%$ DMSO as the co-solvent) for 0.5 h. (d-f) A549 cells pre-treated with NEM (1 mM) and then incubated with DC (10 $\mu \mathrm{M}, 10 \mu \mathrm{M}$ in PBS buffer containing $\approx 1 \%$ DMSO as the co-solvent) for $0.5 \mathrm{~h}$. A549 cells pre-treated with NEM $(1 \mathrm{mM})$, then incubated with DC $(10 \mu \mathrm{M}, 10 \mu \mathrm{M}$ in PBS buffer containing $\sim 1 \%$ DMSO as the co-solvent), and finally incubated with (g-i) Cys $(60 \mu \mathrm{M})$ and $(\mathrm{j}-1) \mathrm{GSH}(60 \mu \mathrm{M})$ for another $0.5 \mathrm{~h}$. The images were acquired using a confocal microscope with $465 \mathrm{~nm}$ excitation and $610 \mathrm{~nm}$ collection.

Fig. 7 (A) Fluorescence imaging of endogenous biothiols in live nude mouse with DC. (1) Blank nude mouse. (2) Subcutaneously injected of NEM (50 $\mu \mathrm{L} 10 \mathrm{mM})$ into the left leg and PBS $(50 \mu \mathrm{L})$ to the right leg areas of interest for $30 \mathrm{~min}$. Followed by the injection of DC (10 $\mu \mathrm{M}, 125 \mu \mathrm{L}$, in PBS buffer containing 5\% DMSO as the co-solvent) into the left and right legs of mouse. The images were then recorded at different times (3) $10 \mathrm{~min}$, (4) $20 \mathrm{~min}$, (5) $30 \mathrm{~min}$ and (6) $40 \mathrm{~min}$, respectively. (B) Mean fluorescence intensity of nude mouse shown in (1-6). The images of nude mouse were recorded with an excitation filter $(465 \mathrm{~nm})$ and an emission filter $(610 \mathrm{~nm})$

Fig. 8 (A) Fluorescence imaging of exogenous biothiols in live nude mouse with DC. (1) Blank nude mouse. (2) Subcutaneously injected of NEM (50 $\mu \mathrm{L} 10 \mathrm{mM})$ into the left 
leg and right leg areas of interest for $30 \mathrm{~min}$. (3) Injection of DC $(10 \mu \mathrm{M}, 125 \mu \mathrm{L}$, in PBS buffer containing 5\% DMSO as the co-solvent) into the left and right legs of mouse. Followed by the injection of Cys $(10 \mu \mathrm{M}, 125 \mu \mathrm{L})$ into the left legs of mouse for (4) $3 \mathrm{~min}$, (5) $6 \mathrm{~min}$, (6) $9 \mathrm{~min}$ and (7) $12 \mathrm{~min}$, respectively. (B) Mean fluorescence intensity of nude mouse shown in (1-7). The images of nude mouse were recorded with an excitation filter (465 nm) and an emission filter $(610 \mathrm{~nm})$.

Fig. 9 (A) Fluorescence imaging of exogenous biothiols in live nude mouse with DC. (1) Blank nude mouse. (2) Subcutaneously injected of NEM (50 $\mu \mathrm{L} 10 \mathrm{mM})$ into the left leg and right leg areas of interest for $30 \mathrm{~min}$. (3) Injection of $\mathbf{D C}(10 \mu \mathrm{M}, 125 \mu \mathrm{L}$, in PBS buffer containing 5\% DMSO as the co-solvent) into the left and right legs of mouse. Followed by the injection of GSH $(10 \mu \mathrm{M}, 125 \mu \mathrm{L})$ into the left legs of mouse for (4) $3 \mathrm{~min}$, (5) $6 \mathrm{~min}$, (6) $9 \mathrm{~min}$ and (7) $12 \mathrm{~min}$, respectively. (B) Mean fluorescence intensity of nude mouse shown in (1-7). The images of nude mouse were recorded with an excitation filter (465 nm) and an emission filter $(610 \mathrm{~nm})$. 

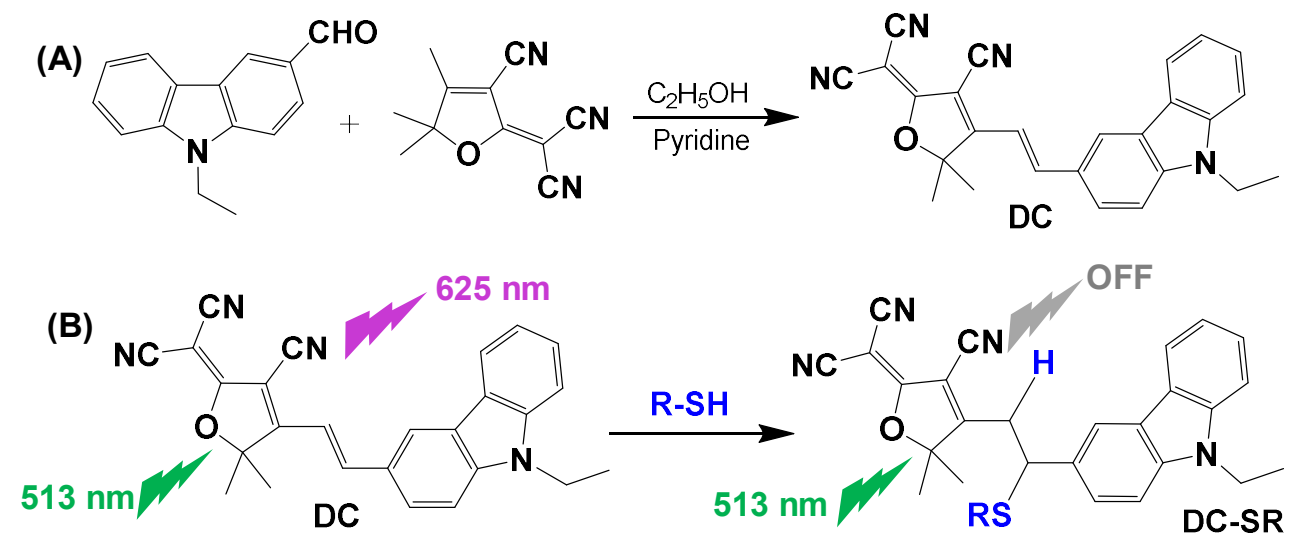

Scheme 1 


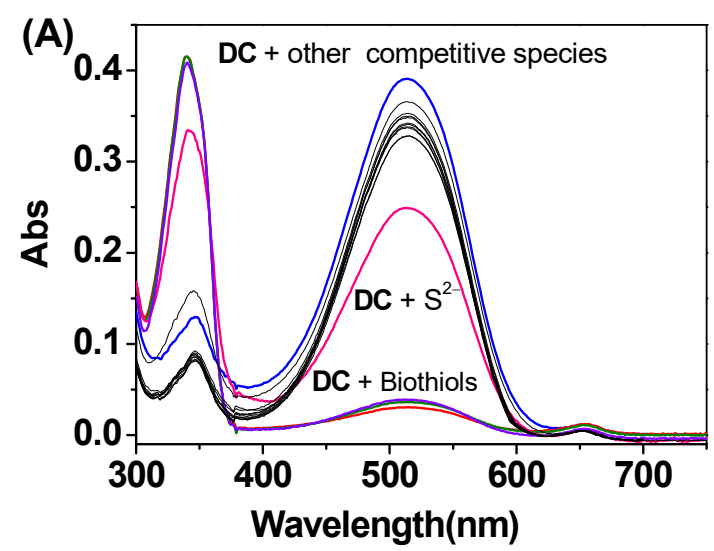

(B)
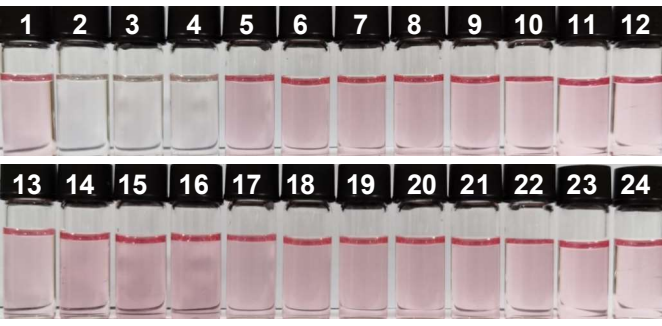

Fig. 1 

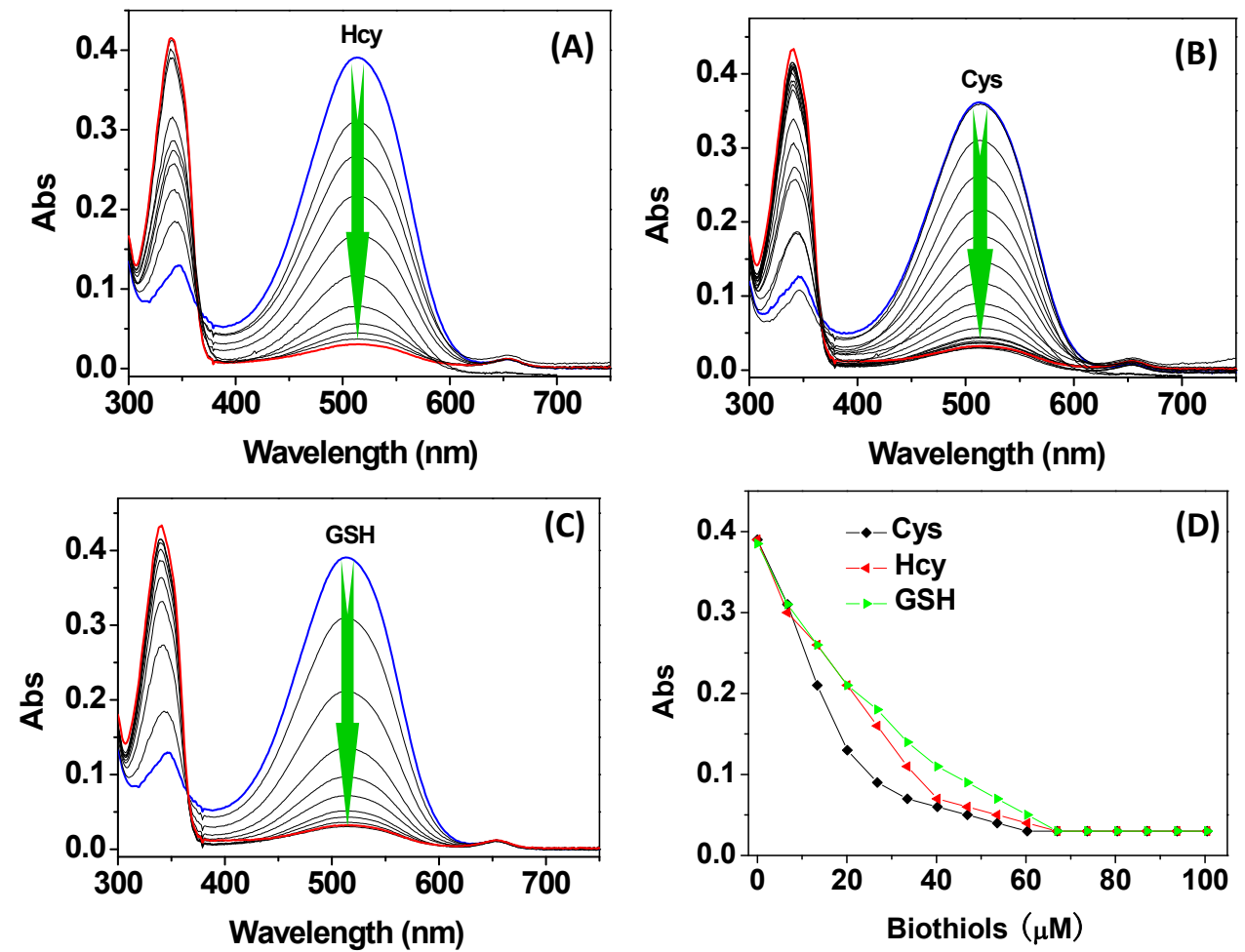

Fig. 2 


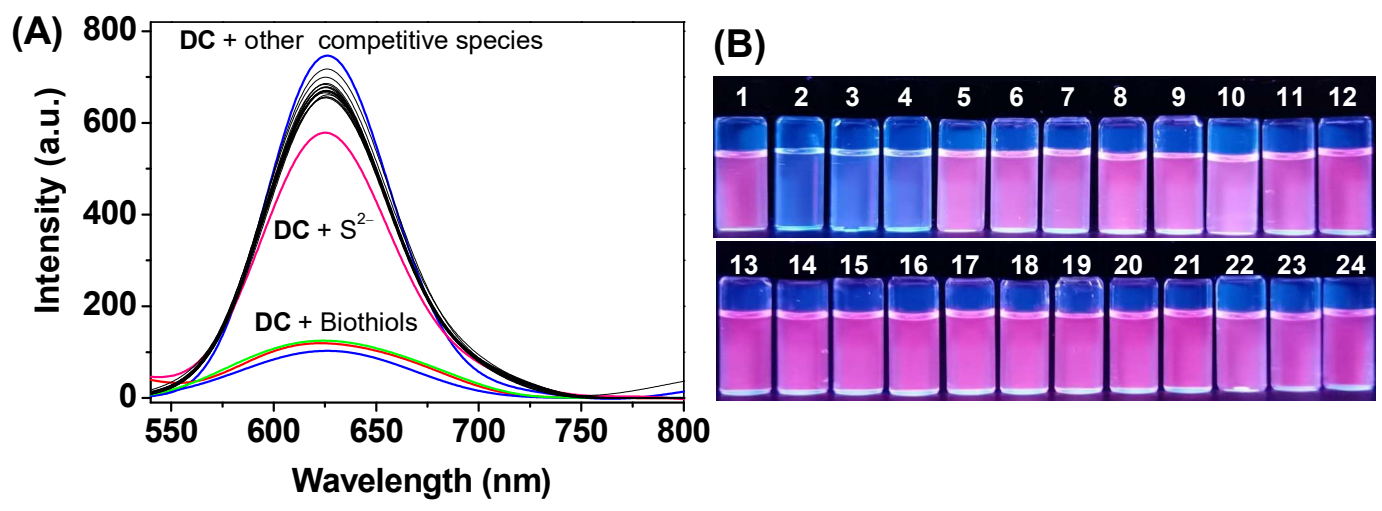

Fig. 3. 

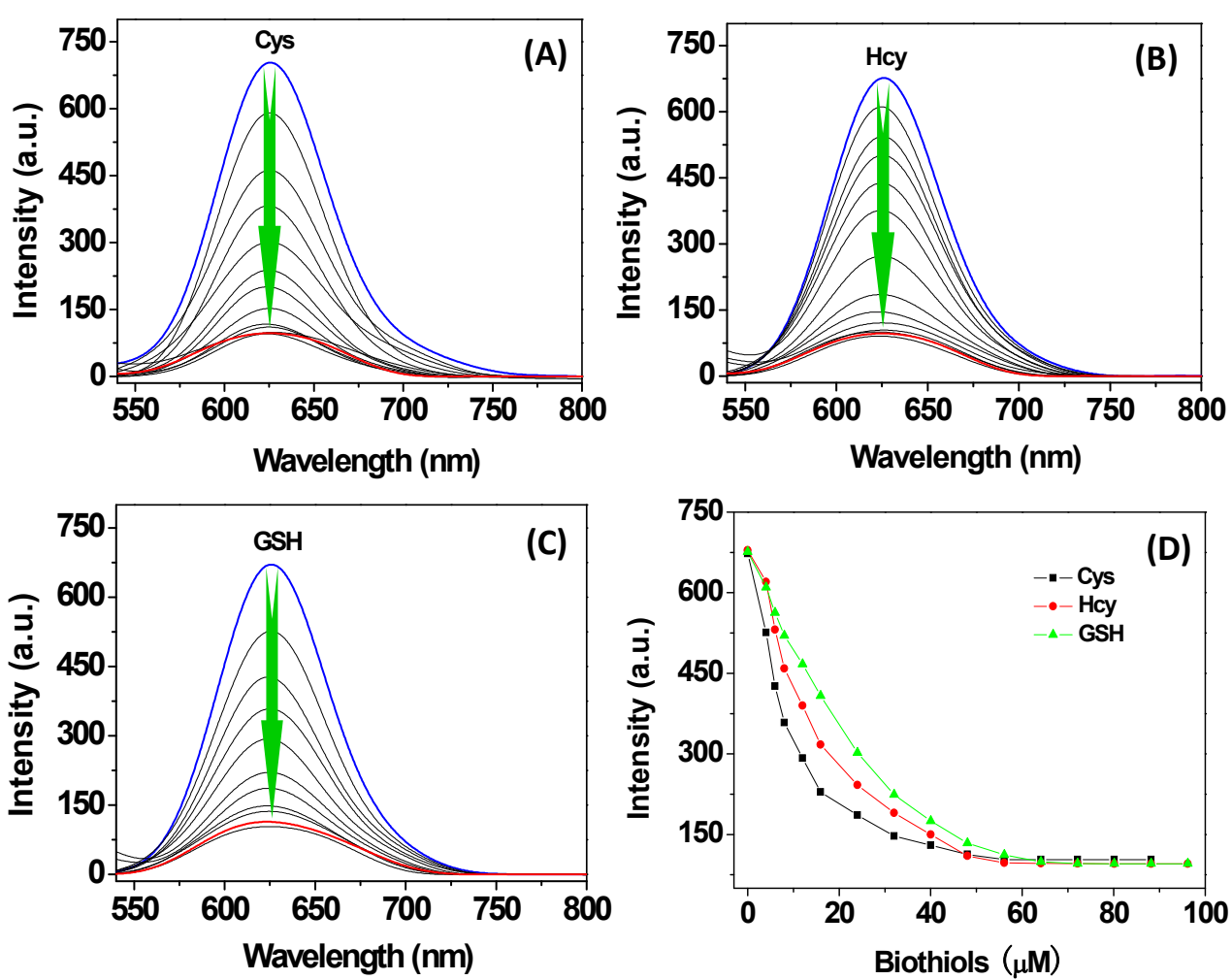

Fig. 4 

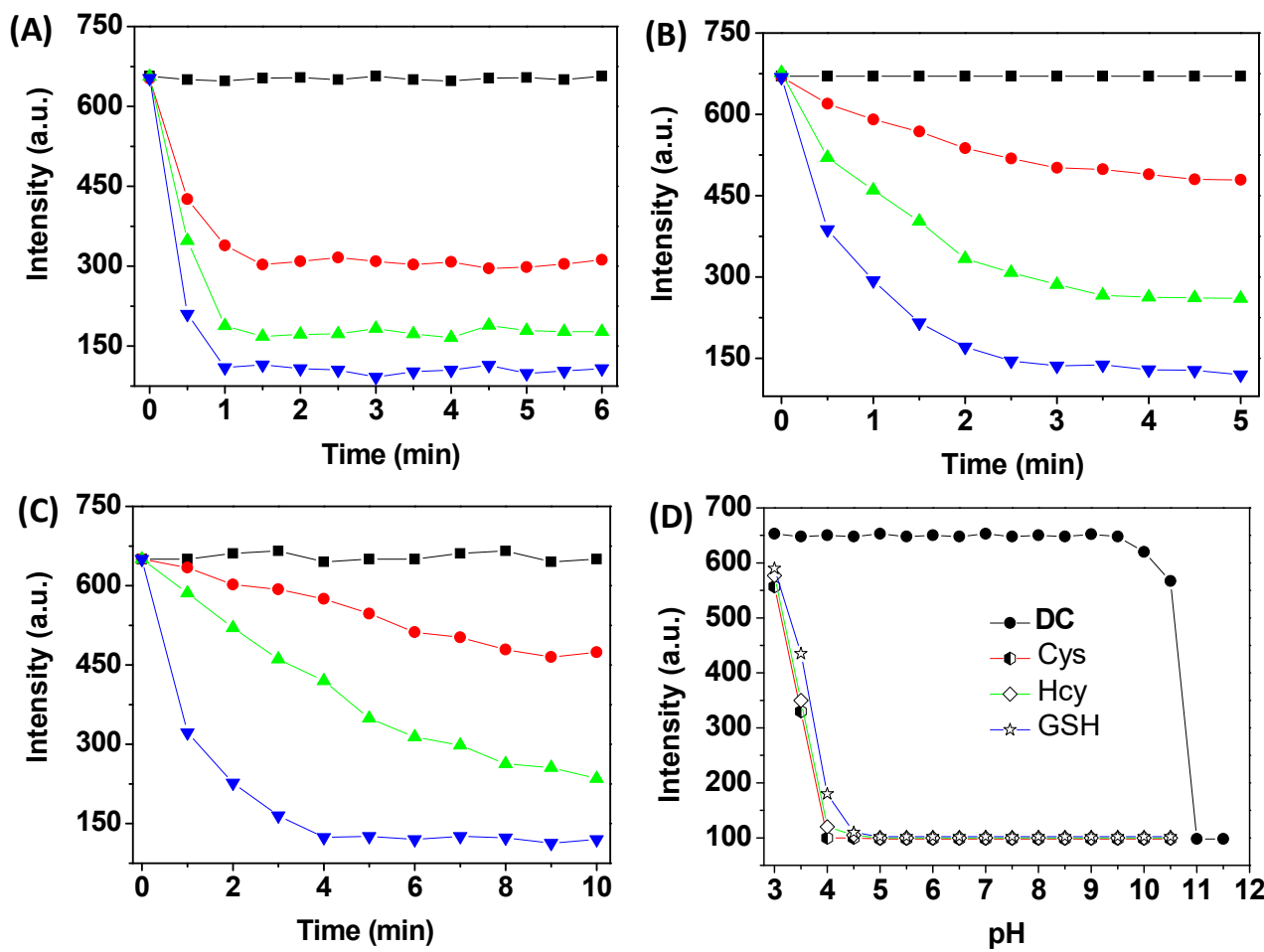

Fig. 5 


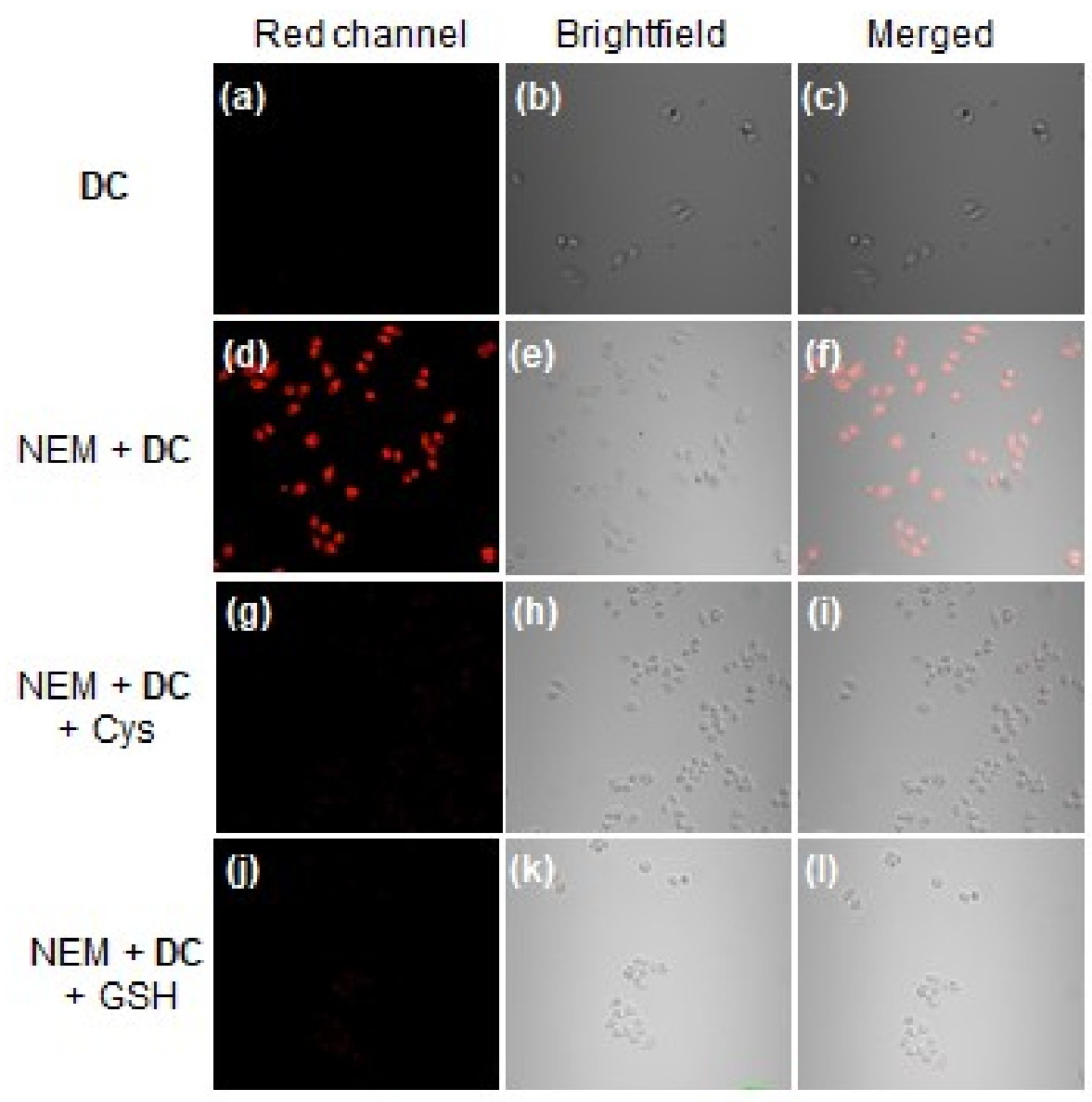

Fig. 6 
(A)

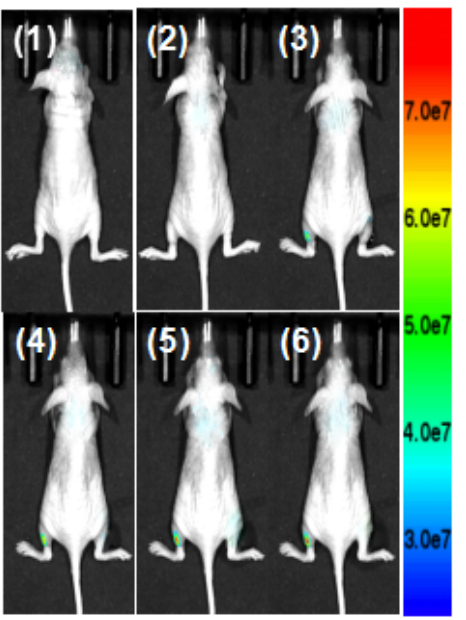

(B) ${ }^{16} \square$ Left leg

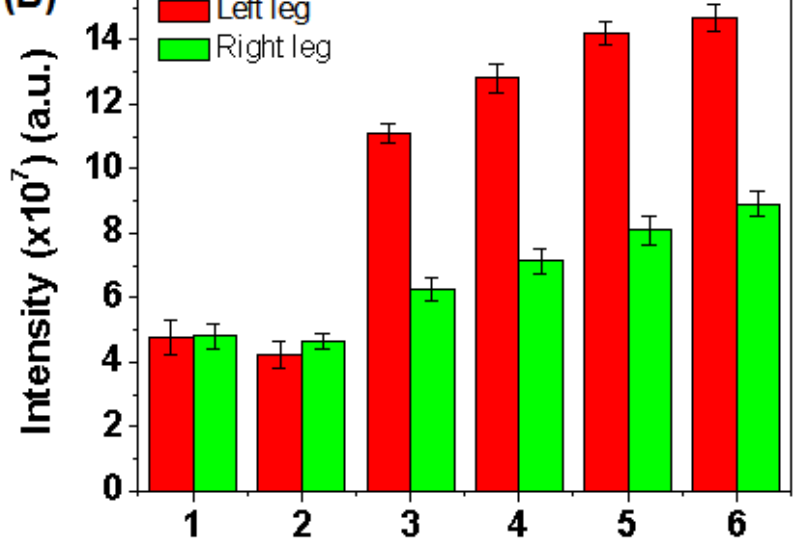

Fig. 7 
(A)

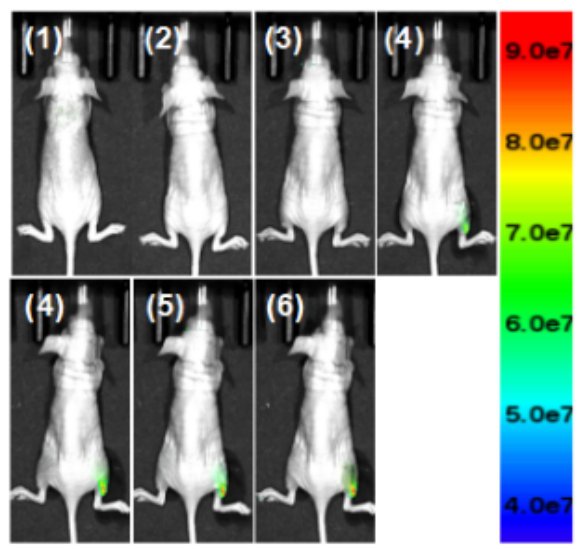

(B) 18 Left leg

- 15 Right leg

胥 15

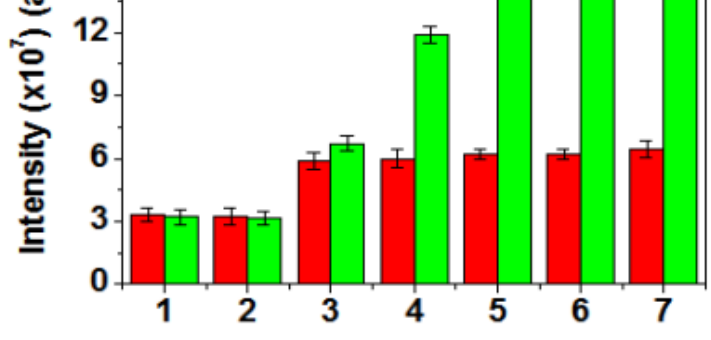

Fig. 8 
(A)

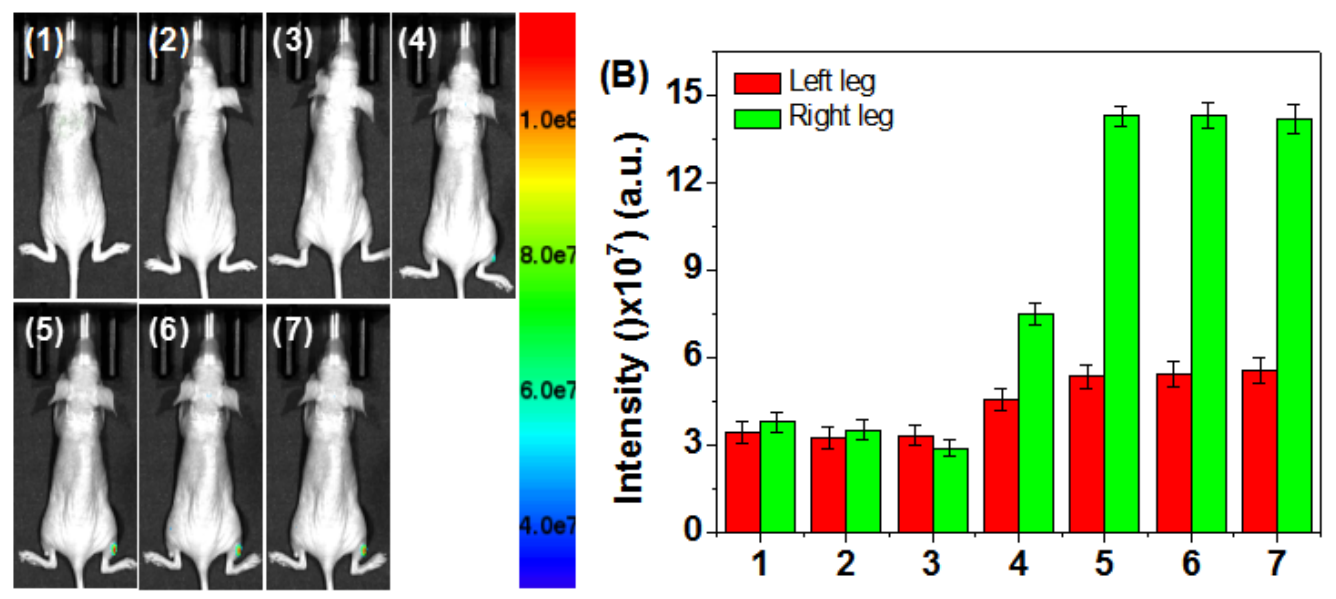

Fig. 9 


\section{Graphical Index}

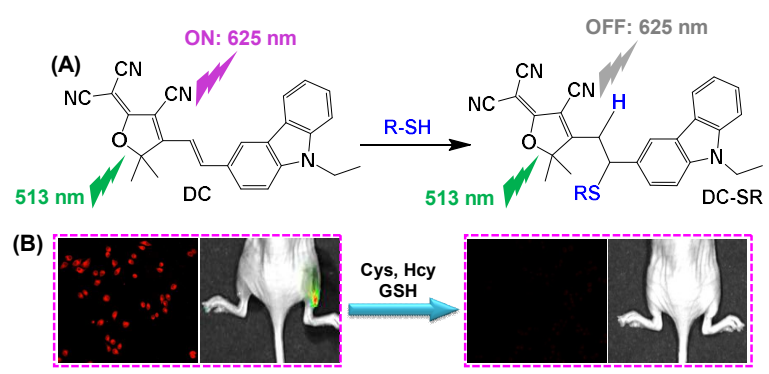

